\title{
Scanning Electrochemical Microscopy for the Electroless Deposition of Gold on Natural Pyrite: Effect of Ferric lons
}

\author{
Aurore Atesyan, ${ }^{[a, b]}$ Oulfa Belhadj ${ }_{1}^{[b]}$ Catherine Combellas, ${ }^{[a]}$ Frédéric Kanoufi, ${ }^{[a]}$ \\ Véronique Rouchon, ${ }^{*[b]}$ and Jean-Marc Noë|*[a]
}

The local electroless deposition of gold on pyrite is studied by scanning electrochemical microscopy (SECM). The SECM and additional SEM experiments provide kinetic and mechanistic insights on the local galvanic replacement of pyrite by gold. We evidence that individual gold nanoparticles or full coverage of gold on the pyrite surface can be obtained by controlling either the deposition time or the flux of gold ions electrogenerated at the ultramicroelectrode. We also studied the influence of ferric

\section{Introduction}

Pyrite $\left(\mathrm{FeS}_{2}\right)$, the most earth abundant metal sulfide mineral, is well-known particularly from palaeontologists and geologists as it is commonly found in sedimentary rocks. For the last two decades, the semi conducting properties of pyrite have become a subject of interest in physical chemistry for the development

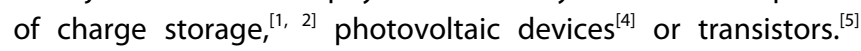
However one of the major drawbacks of this mineral is its low resistance against oxidation leading to its degradation. It is then important to understand the mechanisms implied in the corrosion process at various scales. Pyrite is very sensitive to $\mathrm{O}_{2}$ and $\mathrm{Fe}^{3+}$, which can act as oxidants, as shown by reaction global 1 and 2: ${ }^{[6]}$

$$
\begin{aligned}
& \mathrm{FeS}_{2}+3.5 \mathrm{O}_{2}+\mathrm{H}_{2} \mathrm{O} \rightarrow \mathrm{Fe}^{2+}+2 \mathrm{H}^{+}+2 \mathrm{SO}_{4}^{2-} \\
& \mathrm{FeS}_{2}+8 \mathrm{H}_{2} \mathrm{O}+14 \mathrm{Fe}^{3+} \rightarrow 15 \mathrm{Fe}^{2+}+16 \mathrm{H}^{+}+2 \mathrm{SO}_{4}^{2-}
\end{aligned}
$$

During these reactions, other products such as elemental sulfur, polysulfides, thiosulfate, sulfite, polythionates, hydrogen sulfide can be produced. iron(III)hydroxide, iron(III) oxide and iron(III)oxyhydroxide can also be involved. The formation of these intermdiates strongly depends on the experimental conditions such as $\mathrm{pH}$, oxidant concentration, hydrodynamics, temperature and pressure. ${ }^{[7,8]}$ The oxidation of pyrite has been widely studied under homogeneous conditions and electro-

[a] A. Atesyan, Dr. C. Combellas, Dr. F. Kanoufi, Dr. J.-M. Noël Université Sorbonne Paris Cité, Université Paris Diderot, ITODYS, CNRS UMR 7086

15 rue Jean-Antoine de Baïf, F-75013 Paris, France E-mail: jean-marc.noel@univ-paris-diderot.fr

[b] A. Atesyan, O. Belhadj, Prof. V. Rouchon

Centre de Recherches sur la Conservation, CNRS USR 3224, 36 rue GeoffroySaint-Hilaire, F-75005 Paris, France

E-mail: veronique.rouchon@mnhn.fr

Supporting information for this article is available on the WWW under https://doi.org/10.1002/celc.201801271 ions, known to be implied on gold etching and pyrite corrosion and therefore, on the overall process of gold deposition on pyrite. We then demonstrate that the presence of ferric ions significantly modifies i) the thermodynamic of the gold electrodissolution, ii) the process of adsorption of auric ions on pyrite in the first instants, iii) the number of nucleation sites on the pyrite surface and, iv) the structure of the deposited gold layer.

chemical investigations have permitted to study the kinetics of pyrite oxidation $^{[9]}$ and to evidence the effect of temperature, ${ }^{[10]}$ sulfates $^{[10]}$ acids, $^{[11,12]}$ or chlorides ${ }^{[13]}$ on its oxidation potential. Some works also reported the role of microorganisms such as bacteria in the oxidation of pyrite. ${ }^{[14,15]}$ Other oxidants have been shown to efficiently oxidize pyrite such as hydrogen peroxide $\left(\mathrm{H}_{2} \mathrm{O}_{2}\right)$ that leads to the Fenton reaction, which finds applications in water treatment for the removal of organic contaminants. ${ }^{[17,18]}$ It was also demonstrated that metallic ions such as chromium, ${ }^{[20]}$ silver, ${ }^{[21,22]}$ or gold ${ }^{[23,24]}$ can oxidize pyrite leading to the spontaneous deposition of these metals through galvanic replacement. The mechanism of gold deposition at the surface of pyrite is particularly interesting as it is known to occur in significant amount in pyrite materials and also because its local deposition could be interesting for electronic applications. It is then of primary importance to get kinetics and mechanistic insight about this process. It has already been studied by $\mathrm{SEM}^{[25-28]}$ and $\mathrm{STM}^{[28]}$ in the case of gold nanoparticles deposition at the surface of a pyrite fully immersed in a solution of gold ions. Under such conditions, the substitution of pyrite by gold occurs at the scale of several minutes and displays the formation of holes on the pyrite surface after the re-dissolution of precipitated gold NPs. ${ }^{[3,26]}$ This is due to the galvanic replacement of gold by pyrite as shown in equation 3 resulting in the release of $\mathrm{Fe}^{3+}$ and sulfate. ${ }^{[23,24,26]}$

$$
\begin{aligned}
& \mathrm{FeS}_{2}+8 \mathrm{H}_{2} \mathrm{O}+5 \mathrm{AuCl}_{4}^{-} \rightarrow \\
& 5 \mathrm{Au}^{0}+\mathrm{Fe}^{3+}+16 \mathrm{H}^{+} 2 \mathrm{SO}_{4}^{2-}+20 \mathrm{Cl}^{-}
\end{aligned}
$$

The release of $\mathrm{Fe}^{3+}$ has been shown to possibly delay the nucleation of gold at the pyrite surface, ${ }^{[28]}$ due either to the dissolution of pyrite by $\mathrm{Fe}^{3+}$ (equation 2) or to the specific oxidizing properties of $\mathrm{Fe}^{3+}$ on gold. Indeed, $\mathrm{Fe}^{3+}$ has already been used as a leaching agent for gold dissolution in acidic solution of thiourea ${ }^{[29,30]}$ or more recently to spontaneously oxidize nanorods. ${ }^{[31]}$ The study of the local deposition of gold on pyrite is then of interest to provide new kinetic and 
mecanistic insight particularly in presence of $\mathrm{Fe}^{3+}$. For this reason coupled to the interest of developing methods of lithography on pyrite, local electrochemical strategies are an interesting pathway to study the local electrodeposition of gold on pyrite. Indeed, scanning electrochemical microscopy (SECM) has been used for the local electrodeposition of metallic NPs at various substrates. The local deposition of silver on various substrates may be mentioned. ${ }^{[32-34]}$ Particularly, Unwin's group studied from the SECM transients silver adsorption and nucleation on a pyrite surface at a short time scale $(<1 \mathrm{~s}) \cdot{ }^{[35]}$ The local electrodeposition of cobalt ${ }^{[36]}$ or gold ${ }^{[33,37-44]}$ at various substrates was also studied by SECM with a specific attention to gold deposition on silicon semi conducting substrates ${ }^{[38]}$ and to the electroless deposition of gold. ${ }^{[39-42]}$ However, these approaches need either the connection of the semiconducting substrate, using a precious metal ${ }^{[39,42]}$ or a surface modification step. ${ }^{[40,41]}$ Since the open circuit potential of pyrite is $<0.1 \mathrm{~V}$ vs SCE ${ }^{[45]} \mathrm{SECM}$ is appropriate to study the local and spontaneous deposition of a precious metal at the pyrite surface.

Herein, the local deposition of gold on natural pyrite is investigated by SECM using a gold sacrifical ultramicroelectrode (UME) held near an unbiased pyrite substrate. If the gold deposition is attested by SEM-EDX and SECM analysis, a detailed analysis of the transient of gold dissolution at the UME allows identifying the growth process. The deposition time and the effect of the potential applied at the UME are investigated to extract kinetics information on the deposition process and to discuss the possible mechanisms involved. Finally, the importance of ferric ions on the deposition process on pyrite as well as on the structure of the gold pattern is demonstrated.

\section{Results and Discussion}

\section{Gold Deposition and Transient Analysis}

The first set of measurements was performed in a solution containing $0.05 \mathrm{M} \mathrm{H}_{2} \mathrm{SO}_{4}$ and $0.1 \mathrm{M} \mathrm{KCl}$. Although pyrite is known to progressively dissolve in acidic media, ${ }^{[46,47]}$ at the time scale of our experiments no spontaneous dissolution was observed. This is consistent with previous observation for local silver deposition on pyrite. ${ }^{[35]}$ A $25 \mu$ m diameter gold UME was approached to an unbiased polished surface of a natural pyrite (Mexico, private collection) and then retracted from $\approx 5 \mu \mathrm{m}$. Figure S1 (Supporting Information, SI) shows the linear voltammogram (LV) of the gold UME oxidation in the presence of chloride to generate soluble gold ions $\left(\mathrm{AuCl}_{4}{ }^{-}\right.$mainly). The decay of current observed at a potential above $1,2 \mathrm{~V}$ vs Ag/ $\mathrm{AgCl}$ is due to the formation of gold oxides as reported previously. ${ }^{[48]}$ From this LV the potential at the UME was held at $0.95 \mathrm{~V}$ vs $\mathrm{Ag} / \mathrm{AgCl}$ to dissolve gold in the vicinity of the pyrite surface. The $\mathrm{AuCl}_{4}^{-}$ions generated are then spontaneously reduced at the unbiased pyrite surface following equation 3 (Figure $1 \mathrm{~A}$ ). The deposition was characterized by SEM-EDX analysis. The SEM image shown in Figure S2A (SI) recorded after $10 \mathrm{~s}$ of deposition (or longer times as discussed in the next section) evidences a bright spot at the pyrite

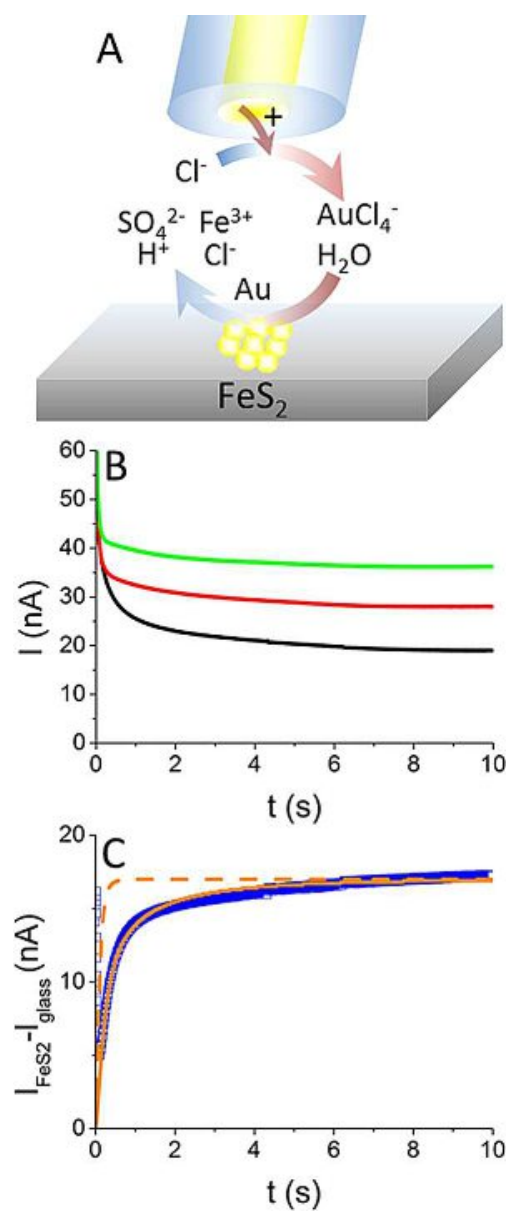

Figure 1. A) General principle of the local deposition of gold onto pyrite in the SECM configuration. B) Transients recorded at a gold UME biased at $0.95 \mathrm{~V}$ vs $\mathrm{Ag} / \mathrm{AgCl}$ in a solution containing $0.1 \mathrm{M} \mathrm{H}_{2} \mathrm{SO}_{4}+0.1 \mathrm{M} \mathrm{KCl}$ in the bulk (-), at $5 \mu \mathrm{m}$ from a glass substrate $(-)$ or a pyrite surface $(-)$. C) (-) Transient obtained from the subtraction of $(-)$ by $(-)$ and compared to the theoretical model based on the nucleation controlled transport from a hemisphere using the parameters $A=8 \mathrm{~s}^{-1}, B=1.7 \mathrm{~s}^{-1 / 2}(-)$ or $7 \mathrm{~s}^{-1 / 2}(--)$ and $C=17 \mathrm{nA}^{\left[{ }^{[1]]}\right.}$

surface with a diameter $2 a_{\text {spot }}=30-40 \mu \mathrm{m}$. The dark area corresponds to the pyrite surface, as confirmed by the characteristic Fe and S peaks in the EDX spectrum (Figure S2B in $\mathrm{SI}$ ). Similar measurements performed in the bright spots (Figure S2C in SI) evidence Au characteristic peaks highlighting the presence of gold on top of the pyrite surface. A zoom on the gold deposit of Figure S2A (SI) evidences the presence of individual NPs of a density of $\mathrm{N} \approx 300 \mu \mathrm{m}^{-2}$ (Figure S3A in SI). The distribution of deposited NPs diameter size displays an average diameter $2 r_{\mathrm{NP}}=30 \pm 12 \mathrm{~nm}$ as shown in Figure S3B (SI).

Chronoamperograms were recorded (Figure 1B) at the UME during gold dissolution under different conditions: i) in the bulk (red curve), ii) at $5 \mu \mathrm{m}$ from a glass insulating substrate (black curve) and, iii) at $5 \mu \mathrm{m}$ from the pyrite surface (green curve). Since the current of gold dissolution is controlled by the rate of gold ions limited itself by the transport of $\mathrm{Cl}^{-}$, it is possible to estimate the concentration of gold ions electrogenerated at the UME. Considering $\mathrm{AuCl}_{4}^{-}$as the only Au-bearing ionic species 
formed during dissolution, one can estimate $C_{\mathrm{AuCl}_{4}^{-}} \approx 1.5 \times$ $10^{-3} \mathrm{molL}^{-1}$ using the diffusion coefficient $D_{\mathrm{AuCl}_{4}^{-}}=1.4 \times$ $10^{-5} \mathrm{~cm}^{2} \mathrm{~s}^{-1}$ from the steady state current (see experimental section). ${ }^{[49]}$

As already shown in the case of gold deposition on an unbiased polyaniline film, ${ }^{[41]}$ the dissolution current is higher when the UME is close to the pyrite surface due to the reduction of $\mathrm{AuCl}_{4}{ }^{-}$to $\mathrm{Au}$ at the surface regenerating $\mathrm{Cl}^{-}$in the vicinity of the UME. However, contrary to the transient observed in the case of silver deposition on pyrite, ${ }^{[35]}$ there is no depletion of the current at short time, suggesting a negligible adsorption of the gold ions at the pyrite surface before the reduction process. ${ }^{[50]}$ If this transient is subtracted from the one recorded at the same distance from a substrate that does not induce gold reduction (here glass) the current $I$ resulting from this subtraction $\left(I=I_{\text {Fes2 }}-I_{\text {glass }}\right.$ Figure $\left.1 C\right)$ reflects the process of gold growth at the pyrite surface.

This subtracted transient was compared to the analytical expression proposed for the mass-transfer controlled nucleation-growth of hemispherical nuclei at microelectrodes by Hyde et $a^{[51]}$ and already adapted to the SECM configuration for the local reduction of poly(tetrafluoroethylene) (expression in equation 4): ${ }^{[52]}$

$I=C\left[1-e\left(\left(-B \sqrt{t}\left\{1-e(-A t)\left[1+(A t / 3)+\left((A t)^{2} / 10\right)\right]\right\}\right]\right.\right.$

where $A$ corresponds to the nucleation rate constant, $B$ to the characteristic growth rate of a single nuclei under the SECM mass transport control and $C$ corresponds to the maximum reduction current observed at long times (here at $10 \mathrm{~s}$ ). The best fit of the experimental transient by this expression is obtained with the parameters $A=8 \mathrm{~s}^{-1}, B=1.7 \mathrm{~s}^{-1 / 2}$ and $C=$ $17 \mathrm{nA}$ (orange solid trace in Figure $1 \mathrm{C}$, Hyde's model) within standard deviations of $3 \mathrm{~s}^{-1}, 0.3 \mathrm{~s}^{-1 / 2}$ and $1 \mathrm{nA}$ for parameters $A$, $B$ and $C$ respectively. The value of the nucleation rate constant $(A)$, suggests that the nucleation of gold on pyrite is progressive rather than instantaneous. This progressive growth tends to a current plateau (the value of $C$ ) traducing the overlap of the diffusion field of $\mathrm{AuCl}_{4}^{-}$consumption at the gold NPs present on the pyrite surface. Indeed, a micrometric array of growing NPs will operate as a micrometric array of nanoelectrodes, which behaves as a microelectrode as long as $N a_{\text {spot }} r_{N P}$ $N^{*} a_{\text {spot }}{ }^{*} r_{N P}>1 .^{[53,54]}$ This situation is actually fulfilled at $10 \mathrm{~s}$ based on the values of $N, a_{\text {spot }}$ and $r_{\mathrm{NP}}$ extracted from Figure S3 (SI). The parameter $\mathrm{B}$ is given by $\mathrm{B}=\lambda \kappa_{\mathrm{r}}^{11 / 2} N_{0}$ where $\lambda$ is a constant related to the characteristic length of mass-transfer, approximated here as the tip-substrate separation distance $d=5 \mu \mathrm{m}$, $N_{0}$ the saturation nucleus density (the active sites) and $\kappa_{\mathrm{r}}^{1 / 2}$ corresponds to the growth rate of individual nuclei. From the data obtained at $10 \mathrm{~s}$ in Figure S3A (SI), $N_{0}=3 \times 10^{10} \mathrm{~cm}^{-2}$, the value of $B$ from the best fit yields $\kappa_{\Gamma}^{\prime 1 / 2}=1.2 \mathrm{~nm} \mathrm{~s}^{-1 / 2}$. Another approach to estimate the growth rate $\kappa_{r}^{1 / 2}$ lies in the quantification of the average radius $r_{N P}: \kappa_{\Gamma}^{11 / 2}=r_{N P} / t^{1 / 2}$. This average radius was estimated from the distribution in the SEM image in Figure S3B (SI): an average $r_{\mathrm{NP}}=15 \mathrm{~nm}$ is found for the NPs formed after $t=10 \mathrm{~s}$, yielding to a growth rate $\kappa_{\mathrm{r}}^{11 / 2}=$
$4,7 \mathrm{~nm} / \mathrm{s}^{1 / 2}$ approximately 4 times higher than what was found previously. The use of this value for the calculation of the parameter $B$ with the former model, leads to an estimation of $B=7 \mathrm{~s}^{-1 / 2}$, and to a poor fit of the experimental curve (orange dash line in Figure 1C). Also the growth of individual NPs is underestimated in the transient. This difference can be explained by a value of $N_{0}$ below the value estimated from the SEM image and/or a tip-substrate distance $d<5 \mu \mathrm{m}$. Another possibility is a multistep nucleation with for example 2 different kinetics of nucleation, leading to two populations of NPs, as proposed previously. ${ }^{[55]}$ However, from the subtracted transient it was not possible to analyze the nucleation process in its first instants and discriminate between both interpretations.

\section{SECM Imaging of Gold Micropattern on Pyrite}

Additionally to the SEM, SECM images were recorded to visualize the gold deposit on the pyrite surface and investigate its electrochemical properties. Experiments were recorded at the same sample using successively $\mathrm{Fe}^{2+}$ and $\mathrm{Ru}\left[\mathrm{NH}_{3}\right]_{6}{ }^{3+}$ as redox probe to minimize the possible alteration of the pyrite surface. Figure S4A (SI) displays approach curves recorded with ruthenium hexamine $\left(\mathrm{Ru}\left[\mathrm{NH}_{3}\right]_{6}{ }^{3+}\right)$, which is a classical outer sphere redox probe, beside and above the gold pattern. Both approach curves present a positive feedback with a charge transfer lightly higher above the gold spot $(K=10)$ traducing a similar apparent conductivity. The positive feedback observed at the surface of the pyrite attests of a good conductivity of the pyrite according to the low sheet resistance $(1,3 \Omega$ at $1 \mathrm{~mA})$ measured using the 4 probe-point method. Conversely, SECM approach curves recorded in a $0.05 \mathrm{M} \mathrm{H}_{2} \mathrm{SO}_{4}+0.1 \mathrm{M} \mathrm{KCl}$ solution containing $50 \mathrm{mM} \mathrm{Fe}\left(\mathrm{SO}_{4}\right) \cdot 7 \mathrm{H}_{2} \mathrm{O}$, (that is with $\mathrm{Fe}^{2+} / \mathrm{Fe}^{3}$ + as the redox probe) are significantly different (Figure $2 \mathrm{~A}$ ). Indeed such a redox probe has already been used to evidence the structure and electrochemical activity of polycrystalline metal electrodes. ${ }^{[56,57]}$ At the pyrite surface, a low $\mathrm{K}$ value was estimated $(K=0.2)$ showing the low regeneration of $\mathrm{Fe}^{3+}$. This low regeneration reveals the high sensitivity of $\mathrm{Fe}^{3+}$ to surface state as previously shown, ${ }^{[56,57]}$ maybe due to the presence of sulphur intermediates at the surface of the pyrite. Above the gold pattern, the approach curve presents a significant increase of $K$ up to a value of 3, traducing a more efficient regeneration of $\mathrm{Fe}^{3+}$. The resulting SECM image recorded at $5 \mu \mathrm{m}$ from the surface (Figure 2B) evidences a gold pattern of about $40 \mu \mathrm{m}$ diameter, with individual NPs unresolved because of the overlapping of their diffusion layers. However, the SECM image recorded with $\mathrm{Ru}\left[\mathrm{NH}_{3}\right]_{6}{ }^{3+}$ shows a poor contrast of the gold spot (Figure S4B in $\mathrm{SI}$ ). In addition to allow the visualisation of the gold deposition by SECM, the use of $\mathrm{Fe}^{2+} / \mathrm{Fe}^{3+}$ as the redox probe evidences the difference of electrochemical activity between pyrite and deposited gold and suggests that some electrochemical processes are promoted on gold. Such electrochemical investigation could be further explored to locate metallic inclusions at the pyrite surface and investigate in situ their influence on the corrosion of pyrite. 

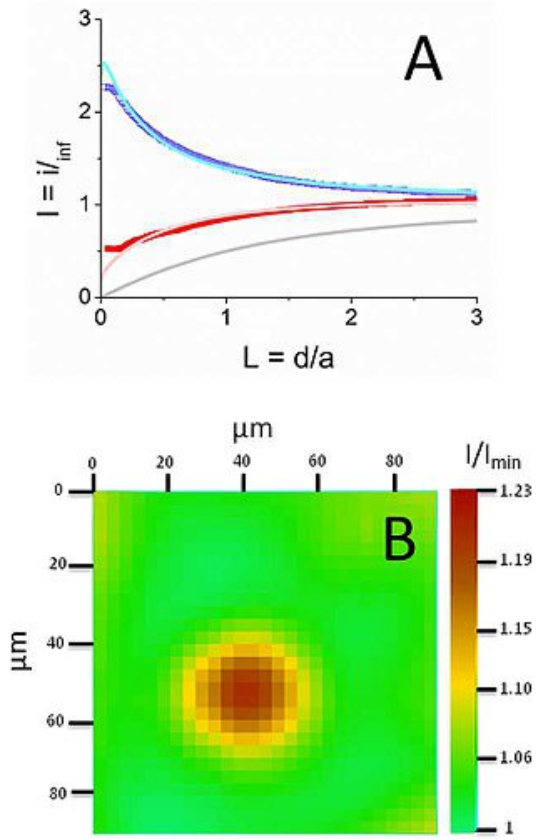

Figure 2. A) SECM approach curves at a $25 \mu \mathrm{m}$ diameter gold UME in a $0.05 \mathrm{M} \mathrm{H}_{2} \mathrm{SO}_{4}+0.1 \mathrm{M} \mathrm{KCl}$ solution containing $50 \mathrm{mM} \mathrm{Fe}\left(\mathrm{SO}_{4}\right) \cdot 7 \mathrm{H}_{2} \mathrm{O}(-)$ on pyrite and ( - ) on a gold pattern obtained in the same solution for $300 \mathrm{~s}$ at $\mathrm{E}=0.95 \mathrm{~V}$ vs $\mathrm{Ag} / \mathrm{AgCl}$. The lines are the theoretical curves for irreversible electron transfer kinetics. (-) Insulating, (-) $\mathrm{K}=0.2,(-) \mathrm{K}=3$. B) Corresponding SECM image obtained at a scan rate of $10 \mu \mathrm{ms}^{-1}$.

\section{Impact of Deposition Duration and Potential}

The influence of the time duration of the applied potential on the structure of gold deposits was investigated by SEM (Figure 3) choosing deposition durations of 10, 20, 40 and $60 \mathrm{~s}$ and maintaining the potential of the UME at $0.95 \mathrm{~V} v \mathrm{Ag} / \mathrm{AgCl}$. Figure $3 \mathrm{~A}$ evidences the presence of four bright spots characteristic of the gold deposition. The comparable diameter of the gold deposits for the different deposition durations (35 to $45 \mu \mathrm{m}$ diameter) evidences the limitation of the expansion of the gold spot suggesting accumulation of gold on top of the spot at longer time. At short deposition duration (10 s), only small sized individual NPs (10 to $50 \mathrm{~nm}$ diameter) are observed as well as few agglomerates (Figure 3B) consistent with previous observation of silver deposition. ${ }^{[35]}$ The increase of deposition duration to $20 \mathrm{~s}$ leads to the progressive covering of the pyrite surface by gold and to the coalescence of the NPs (Figure $3 \mathrm{C}$ ) as suggested from the SECM transient analysis (Figure 1). After $40 \mathrm{~s}$ (Figure 3D) of deposition only few areas of the pyrite surface remain free of gold and the deposit is almost homogeneous. After $60 \mathrm{~s}$ (Figure 3E) of deposition the pyrite surface is fully covered and excrescences of gold are observed corresponding to a vertical growth of the gold film. This was further evidenced after $1800 \mathrm{~s}$ of deposition since then the gold deposit becomes relatively thick $(>1 \mu \mathrm{m})$ as shown in the SEM image in Figure S5 (SI). Interestingly, this gold deposit appears extremely robust since it was not significantly damaged after sonication in water for $300 \mathrm{~s}$. Such robust and homogeneous layer of gold attests of a negligible effect either of the pyrite

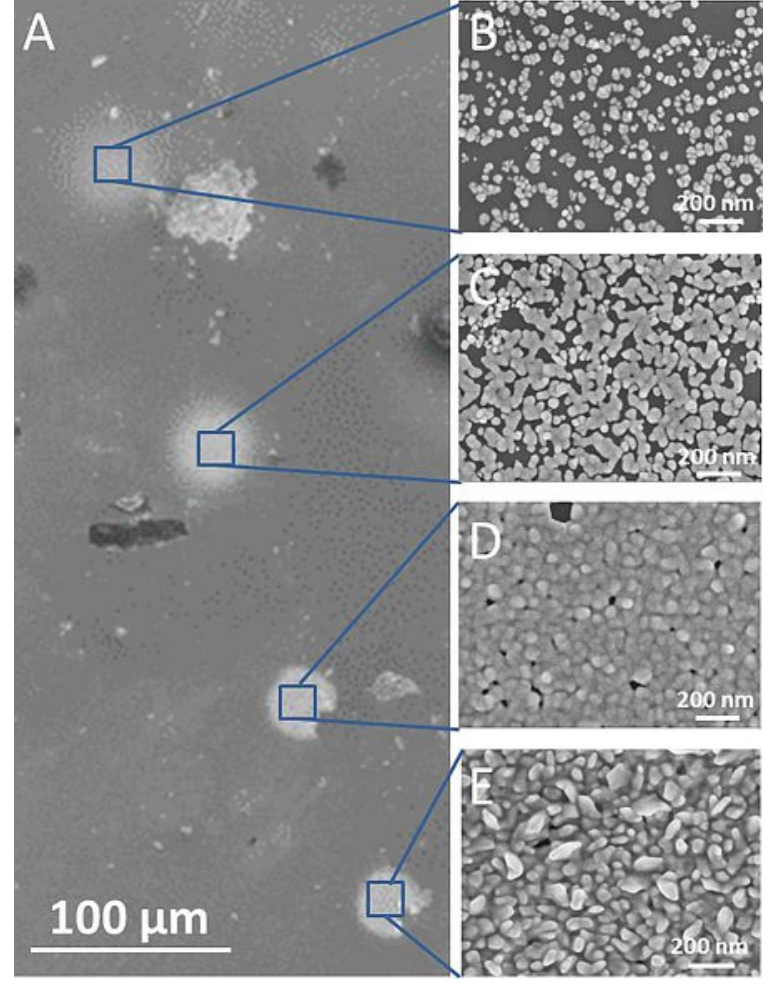

Figure 3. A) SEM images of gold deposition performed for (B) 10, (C) 20, (D) 40 , and (E) $60 \mathrm{~s}$ in a $0.1 \mathrm{M} \mathrm{H}_{2} \mathrm{SO}_{4}+0.1 \mathrm{M} \mathrm{KCl}$ solution; gold UME biased at $\mathrm{E}=0.95 \mathrm{Vvs} \mathrm{Ag} / \mathrm{AgCl}$ and held at a $5 \mu \mathrm{m}$ distance from the pyrite surface.

dissolution and/or of its modification by sulphur compounds on the gold deposition process.

If the potential applied to the UME is increased to $1.15 \mathrm{~V}$ vs $\mathrm{Ag} / \mathrm{AgCl}$ the current of dissolution recorded (Figure S6A in $\mathrm{SI}$ ) is more than 10 times higher than that recorded at $0.95 \mathrm{~V}$ (Figure 1B) giving a concentration of generated $\mathrm{AuCl}_{4}^{-}$:

$C_{A u C_{4}^{-}} \approx 2 \times 10^{-2} \mathrm{~mol} \mathrm{~L}^{-1}$. Under such conditions, after $10 \mathrm{~s}$ of deposition the coalescence of NPs is already visible (Figure S6B in $\mathrm{SI}$ ) whereas at $\mathrm{E}=0.95 \mathrm{~V}$ vs $\mathrm{Ag} / \mathrm{AgCl}$ (Figure $3 \mathrm{~B}$ ) individual NPs were observed. This coalescence suggests an increase of the number of nucleation spots. This is indeed confirmed by an SEM image performed after $1 \mathrm{~s}$ of deposition (Figure S6C in $\mathrm{SI}$ ) in which individual NPs of similar shape and higher density were obtained. The faster formation of a larger number of gold nuclei surface linked to the increase of $\mathrm{AuCl}_{4}^{-}$concentration traduces a faster rate of $\mathrm{AuCl}_{4}^{-}$reduction on the pyrite surface, typically a higher value of the term $B$ in equation 4 . This allows concluding that the kinetics of the reaction between $\mathrm{AuCl}_{4}^{-}$and the pyrite is not a limiting step.

\section{Mechanism of Gold Deposition}

The spontaneous deposition of gold on pyrite can be explained by two mechanisms. In the first one pyrite is substituted by $\mathrm{Au}^{0}$ under the UME, as proposed from studies performed in gold ions solutions ${ }^{[23,24,26]}$ (Figure $1 A$, equation 3). However, the process would be limited by the direct accessibility of the pyrite 
surface. Indeed, the direct substitution seems to be limited since the pyrite surface is almost fully covered by Au according to SEM pictures (Figure 3E and Figure S5 in $\mathrm{SI}$ ). The possibility to grow further the gold deposit "vertically" at the micrometre scale, suggests that another scenario should be considered. In the SECM configuration the localized formation of $\mathrm{AuCl}_{4}^{-}$ coupled to the conductive properties of pyrite makes possible the reduction of $\mathrm{AuCl}_{4}^{-}$at the pyrite surface (equation 4) concomitantly to the pyrite corrosion (equation 5 ) outside the area of the UME functioning as a bipolar electrode, ${ }^{[58]}$ according to a corrosion mechanism of pyrite already proposed. ${ }^{[11]}$

$\mathrm{AuCl}_{4}^{-}+3 e^{-} \rightarrow \mathrm{Au}^{0}+4 \mathrm{Cl}^{-}$

$\mathrm{FeS}_{2}+8 \mathrm{H}_{2} \mathrm{O} \rightarrow \mathrm{Fe}^{3+}+16 \mathrm{H}^{+}+2 \mathrm{SO}_{4}^{2-}+15 e^{-}$

Since the size of the pyrite substrate is significantly higher than that of the microelectrode this substrate can be considered as an infinite source of electron thus allowing the deposition of a significant amount of gold (Figure S5 in SI), as schematized in Figure 4.

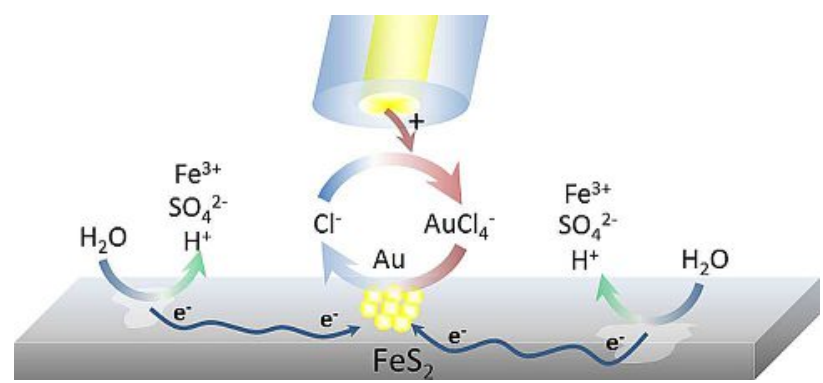

Figure 4. Mechanism of gold deposition under SECM conditions.

\section{Impact of Ferric lons}

As discussed in the introduction, $\mathrm{Fe}^{3+}$ could be involved in the process of gold deposition on pyrite. Moreover, if $\mathrm{Fe}^{3+}$ ions have been shown to selectively etch gold facets in the bulk, ${ }^{[59,60]}$ to the best of our knowledge their effect on the gold electrodeposition has never been explored. However since $\mathrm{Fe}^{3+}$ is also known to accelerate the corrosion of pyrite, ${ }^{[61,62]}$ it is proposed here to use the SECM tip to generate locally and simultaneously $\mathrm{Fe}^{3+}$ from the oxidation of $\mathrm{Fe}^{2+}$, and $\mathrm{AuCl}_{4}^{-}$. Thus, in such a configuration the electrodeposition of gold on pyrite is possible at the expense of the corrosion of pyrite by $\mathrm{Fe}^{3+}$.

The SECM experiments were performed in $0.05 \mathrm{M} \mathrm{H}_{2} \mathrm{SO}_{4}+$ $0.1 \mathrm{M} \mathrm{KCl}$ solution containing $50 \mathrm{mM} \mathrm{Fe}\left(\mathrm{SO}_{4}\right) \cdot 7 \mathrm{H}_{2} \mathrm{O}$. SEM investigations of pyrite after its local exposition to $\mathrm{Fe}^{3+}$ (generated locally at the UME at about $5 \mu \mathrm{m}$ from the pyrite surface by applying a potential of $0.6 \mathrm{~V}$ vs $\mathrm{Ag} / \mathrm{AgCl}$ ) evidences no apparent dissolution of pyrite even for a long time of exposition ( $5 \mathrm{~h}$, data not shown). This can be explained by i) the reduction of $\mathrm{Fe}^{3+}$ to $\mathrm{Fe}^{2+}$ at the pyrite surface followed by the fast charge evacuation outside the area of the UME as shown from the $K$ value determined from the approach curve of Figure $2 \mathrm{~A}$ and ii) the slow dissolution of pyrite in presence of $\mathrm{Fe}^{3+} \cdot[63]$

LVs of gold dissolution in a $0.05 \mathrm{M} \mathrm{H}_{2} \mathrm{SO}_{4}+0.1 \mathrm{M} \mathrm{KCl}$ solution containing various contents of $\mathrm{Fe}^{\prime \prime}\left(\mathrm{SO}_{4}\right) \cdot 7 \mathrm{H}_{2} \mathrm{O}$ are shown in Figure 5A. In order to compare easily the different
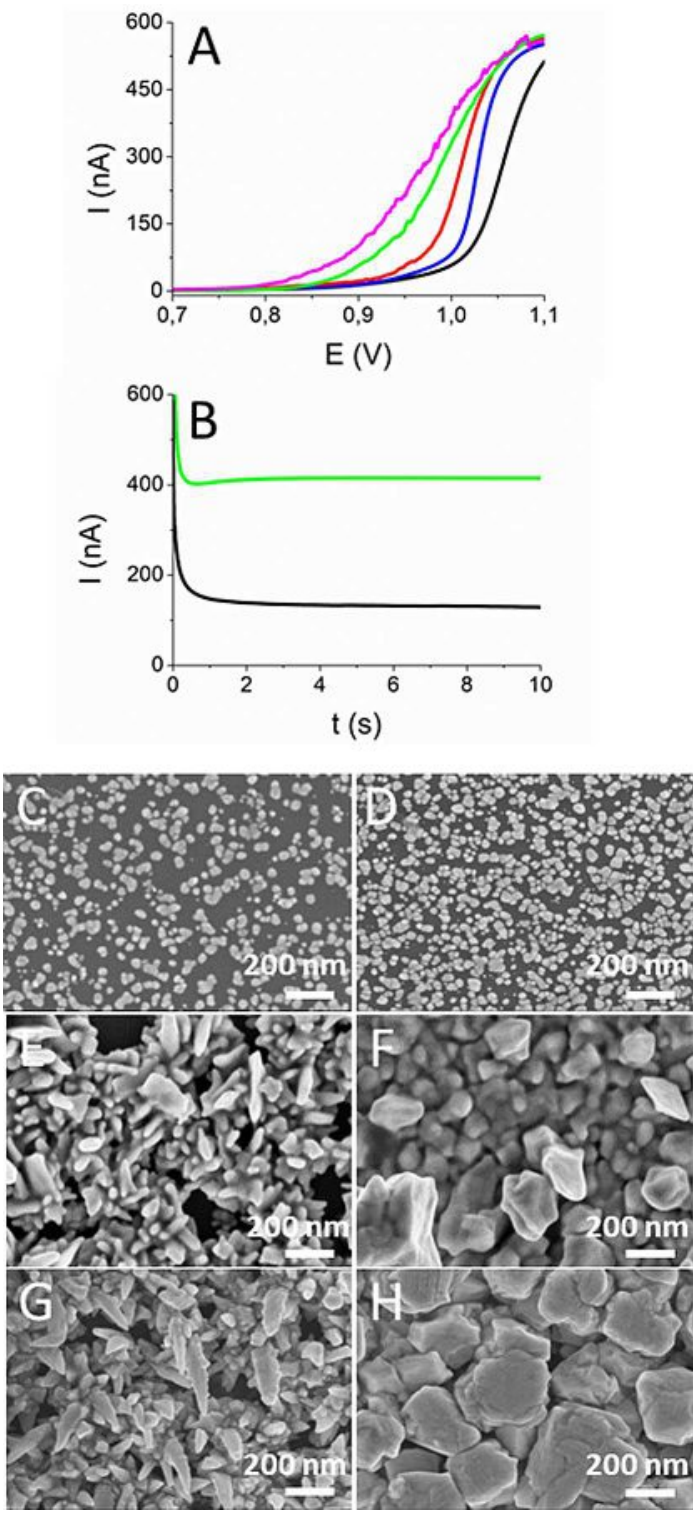

Figure 5. A) Linear voltammograms recorded at a scan rate of $50 \mathrm{mVs}^{-1}$ at a $25 \mu \mathrm{m}$ diameter gold $\mathrm{UME}$ in a $0.1 \mathrm{M} \mathrm{H}_{2} \mathrm{SO}_{4}+0.1 \mathrm{M} \mathrm{KCl}$ solution containing $\mathrm{Fe}^{2+}$ at concentration $\left.\mathrm{O}(-), 5(-), 15(-), 50(-)\right)$, and $\left.100 \mathrm{mM}(-) . \mathrm{B}\right)$ Transient recorded at the gold UME in the bulk (-) and at $5 \mu \mathrm{m}$ from a pyrite surface ( -$)$ ). id = (C to H) SEM images of the gold deposits obtained by applying $\mathrm{E}=0.95 \mathrm{~V}$ vs Ag/AgCl at the UME at a $5 \mu \mathrm{m}$ distance from the pyrite surface in a $0.1 \mathrm{M} \mathrm{H}_{2} \mathrm{SO}_{4}+0.1 \mathrm{M} \mathrm{KCl}$ solution without $(C, E, G)$ or with $(\mathrm{D}, \mathrm{F}, \mathrm{H}) \mathrm{Fe}^{2+}(50 \mathrm{mM})$. Durations of deposition: (C-D) $10 \mathrm{~s}$, (E-F) $300 \mathrm{~s},(\mathrm{G}-\mathrm{H})$ $600 \mathrm{~s}$.

LVs, the steady state plateau current corresponding to the oxidation of $\mathrm{Fe}^{2+}$ to $\mathrm{Fe}^{3+}$ was used as the background for all concentrations of $\mathrm{Fe}^{2+}$, as shown in Figure $\mathrm{S7}$ (SI). A progressive 
shift of the gold oxidation until $150 \mathrm{mV}$ toward negative potentials is observed with increasing concentrations of $\mathrm{Fe}^{2+}$ in solution (from 0 to $100 \mathrm{mM}$ of $\mathrm{Fe}^{2+}$ ). This phenomenon was tested in a $50 \mathrm{mM} \mathrm{Fe}^{3+}$ aqueous solution. Since $\mathrm{FeCl}_{3}$ was used as the iron salt, to keep the concentration of chloride constant at $0.2 \mathrm{M} 50 \mathrm{mM} \mathrm{KCl}$ was added to the solution; this allows excluding any possible effect of $\mathrm{Cl}-$ in the dissolution of gold and any potential shift of the $\mathrm{Ag} / \mathrm{AgCl}$ reference. $\mathrm{A}$ negative potential shift, similar to that observed above, occurred in the $\mathrm{Fe}^{3+}$ solution (Figure $\mathrm{S} 8$ in $\mathrm{SI}$ ). This allows attributing the negative shift to the $\mathrm{Fe}^{3+}$ ions generated at the UME and suggests a thermodynamically favourable oxidation of gold in the presence of $\mathrm{Fe}^{3+}$ which could be for example due to a complexation between $\mathrm{Fe}^{3+}$ and $\mathrm{AuCl}_{4}^{-}$. It is interesting to note here the presence of current noise on the LVs, particularly for high concentration of $\mathrm{Fe}^{2+}(50$ and $100 \mathrm{mM})$. It corresponds to oxidative nano impacts of gold NPs at the UME. These NPs were generated from the reduction of gold ions by $\mathrm{Fe}^{2+}$. A similar local electrosynthesis of silver NPs from electrogenerated $\mathrm{Ag}^{+}$ in the presence of $\mathrm{Fe}^{2+}$ was previously described. ${ }^{[64]}$

Finally, gold was dissolved to $\mathrm{AuCl}_{4}^{-}$at a distance of $5 \mu \mathrm{m}$ from the pyrite surface, by applying a potential of $0.95 \mathrm{~V}$ vs Ag/ $\mathrm{AgCl}$ in a solution containing $50 \mathrm{mM} \mathrm{Fe}^{2+}$. The transients of gold dissolution shown in the green curve of Figure 5B, evidence the absence of noise suggesting the limited solutionphase formation of NPs during the process. It can be due to the confinement effect, which disturbs the flux of reactant, particularly $\mathrm{Fe}^{2+}$, acting as a reducer to produce the NPs. ${ }^{[64]}$ After $\mathrm{Fe}^{2+} / \mathrm{Fe}^{3+}$ current contribution (taken as the background) subtraction, the UME current is about 8 times higher than without $\mathrm{Fe}^{3+}$ at the same potential and at the same distance from the pyrite (Figure 1B, green curve) traducing the facilitated dissolution of gold by $\mathrm{Fe}^{3+}$. A depletion of the current at the beginning of the transient $(t<2 s)$ can be seen, which is characteristic of the uptake of gold ions on the pyrite surface. Such phenomenon has already been observed with other metallic ions on surfaces. ${ }^{[35,50]}$ This result, not observable at the same distance from a glass substrate (Figure 5B, black curve), is confidently attributed to the uptake of gold ions at the pyrite surface due to the presence of $\mathrm{Fe}^{3+}$, as suggested in previous work. $^{[28]}$ Then, the deposition of gold was compared to the one obtained under the same conditions, yet without $\mathrm{Fe}^{2+}$. Figure $5 C$ and $D$ presents SEM images of gold deposits obtained after $10 \mathrm{~s}$ without and with $\mathrm{Fe}^{2+}$ respectively. In the presence of $\mathrm{Fe}^{2+}$ the density of gold NPs is significantly higher at the pyrite surface, according to previous results obtained at higher potential (Figure S6B in SI). For longer deposition times (300 s and $600 \mathrm{~s}$ ), the gold deposits obtained without $\mathrm{Fe}^{2+}$, present progressive classical dendritic growth (Figures $5 \mathrm{E}$ and $\mathrm{G}$ ) as already observed. ${ }^{[43]}$ When $\mathrm{Fe}^{2+}$ is simultaneously oxidized with gold at the UME, the deposition on pyrite is significantly different. Indeed, after $300 \mathrm{~s}$ (Figures 5F and H), pseudo spherical particles of about $200 \mathrm{~nm}$ diameter are observed and progressively grow and coalesce. These observations demonstrate that $\mathrm{Fe}^{3+}$ significantly affects the structure of gold deposits, probably because of the selective etching of gold by $\mathrm{Fe}^{3+}$ during the growth process, as already evidenced at the nanoscale. ${ }^{[1,59]}$ This should be further explored with other metals deposition as it is of major importance for all applications in which dendritic growth has to be avoided, as for lithography or battery applications.

\section{Conclusions}

The galvanic replacement of pyrite by gold at the local scale was studied by SECM. The process of gold deposition was shown to be progressive and the rate of nucleus growth was extracted from the analysis of the transient UME current. The growth rate obtained is slightly underestimated compared to the one calculated from the size of NPs obtained in the SEM images, suggesting a possible multistep nucleation process. Additional SECM imaging evidenced that $\mathrm{Fe}^{2+} / \mathrm{Fe}^{3+}$ is a selective redox probe allowing the distinction between the gold deposit and the pristine pyrite surface. Such redox probe could be further used to localize metallic inclusions in pyrite and investigate in situ their influence on the corrosion of pyrite. Additionally, individual NPs or full coverage of gold on the pyrite surface can be obtained by controlling either the deposition time or the flux of gold ions electrogenerated at the UME, demonstrating that SECM could be an alternative lithographic process of pyrite for the development of various electronic devices. In a more fundamental aspect, the possibility to grow a micrometer thick film of gold on the pyrite surface suggests that the process of deposition is analogous to the functioning of a bipolar electrode. Finally the presence of ferric ions, known to be implied on gold etching and pyrite corrosion, significantly affects the overall process of gold deposition on pyrite starting from electrodissolution of gold, which is thermodynamically more favourable. Moreover, this etching property of $\mathrm{Fe}^{3+}$ was shown as a possible cause of i) the adsorption of auric ions on the pyrite surface evidenced from the transient recorded at the UME that traduces a delay of the nucleation ii) the more homogeneous structure of the gold deposit obtained, which is promising for controlling the dendritic formation during the deposition of metals on surfaces.

\section{Experimental Section}

Chemicals: Iron"' trichloride $\left(\mathrm{FeCl}_{3}\right)$ and hexaammineruthenium ${ }^{\text {III }}$ chloride $\left(\mathrm{Ru}\left(\mathrm{NH}_{3}\right)_{6} \mathrm{Cl}_{3}\right)$, were purchased from Sigma-Aldrich, iron" sulfate $\left(\mathrm{Fe}^{\text {ll }} \mathrm{SO}_{4} \cdot 7 \mathrm{H}_{2} \mathrm{O}\right), \mathrm{KCl}$ from Acros and $\mathrm{H}_{2} \mathrm{SO}_{4}$ from Aldrich.

Surfaces preparation and modification: pyrite surfaces were polished using first water and diamond pads $(74,3$ and $0.25 \mu \mathrm{m}$ grains, Struers), then a colloidal silica suspension $(0.04 \mu \mathrm{m}$ OP-U NonDry, Struers). They were afterwards carefully washed with ultrapure water before each experiment.

Resistance sheet of the pyrite was measured using a Pro4-440N four point resistivity system from Signatone.

Homemade UMEs were fabricated using 1.0/0.5 mm (outer/inner diameter) borosilicate glass capillaries (Sutter Instruments, Novato, California), a $25 \mu \mathrm{m}$ diameter Au wire (99.99\%, Goodfellow Cambridge Ltd., Huntingdon, England), and a laser pipette puller (Narishige, Model\# PC-10, London, U.K.). The obtained $25 \mu \mathrm{m}$ 
diameter disc electrodes presented a RG of $10\left(\mathrm{RG}=r_{g} / a\right.$, where $r_{g}$ is the radius of the insulating glass and $a$ the radius of the gold wire). They were carefully polished on polishing aluminium oxide tape $(3 \mu \mathrm{m})$ from Precision Surfaces International (Houston, Texas).

SECM experiments and electrochemical measurements were performed using a $\mathrm{CH} 1910 \mathrm{~B}$ instrument ( $\mathrm{CH}$-Instruments). A 3-electrode setup was used with $\mathrm{Ag} / \mathrm{AgCl}$ as the reference and $\mathrm{Pt}$ as the counter electrode. An approach curve consists of recording the normalized current $I=I / I_{\text {inf }}$ plotted versus the normalized distance $L=d / a$ (where $I$ is the current at the UME localized at a distance $d$ from the substrate). $I_{\text {inf }}$ is the steady-state current when the UME is at an infinite distance from the substrate: $l_{\text {inf }}=4 n F D C a$, where $n$ is the number of electrons transferred per redox species, $F$ is the Faraday constant, $D$ and $C$ are the diffusion coefficient and the initial concentration of the mediator, respectively. The feedback character determined in the approach curves is characterized by the dimensionless apparent charge transfer rate constant $K$, which is the apparent constant for the reaction between the reduced redox probe and the surface under analysis. ${ }^{[65]}$ The $K$ values were determined from adjustments between the experimental approach curves and the dimensionless theoretical curves assuming irreversible electron transfer kinetics using semi empirical solutions already published. ${ }^{[65-69]}$ Before probing the Pyrite surface, Approach curves were systematically performed at an insulating surface (typically glass) to deduce the electrode-surface distances. The methodology consists in adjusting the experimental curve on the theoretical fit for a negative feedback. Then without removing the UME from the setup approach curves at the pyrite surface were adjust on the other theoretical fits keeping electrode-surface distance determined at the insulating substrate.

\section{Acknowledgements}

We gratefully thank Ludovic Mouton from ITODYS laboratory (University of Paris Diderot) for SEM images. We also acknowledge the French state funds managed by the ANR within the "Investissements d'Avenir" program (reference ANR-11-IDEX-0004-02) for financial support within the framework of the Cluster of Excellence MATISSE.

\section{Conflict of Interest}

The authors declare no conflict of interest.

Keywords: Scanning electrochemical microscopy - local deposition $\cdot$ galvanic replacement $\cdot$ gold $\cdot$ pyrite

[1] A. Dubey, S. K. Singh, B. Tulachan, M. Roy, G. Srivastava, D. Philip, S. Sarkar, M. Das, RSC Adv. 2016, 6, 16859-16867.

[2] R. Tan, J. Yang, J. Hu, K. Wang, Y. Zhao, F. Pan, Chem. Commun. 2016, 52, 986-989.

[3] Z. Hu, Z. Zhu, F. Cheng, K. Zhang, J. Wang, C. Chen, J. Chen Energy Environ. Sci. 2015, 8, 1309-1316.

[4] C. Steinhagen, T. B. Harvey, C. J. Stolle, J. Harris, B. A. Korgel, J. Phys. Chem. Lett. 2012, 3, 2352-2356.

[5] X. Liu, J. Y. L. Ho, M. Wong, H. S. Kwokc, Z. Liu, RSC Adv. 2016, 6, 82908296.

[6] P. C. Singer, W. Stumm, Science 1970, 167, 1121-1123.
[7] J. D. Rimstidt, D. J. Vaughan, Geochim. Cosmochim. Acta 2003, 67, 873880.

[8] A. P. Chandra, A. R. Gerson, Surf. Sci. Rep. 2010, 65, 293-315.

[9] H. Sun, M. Chen, L. Zou, R. Shu, R. Ruan, Hydrometallurgy 2015, 155, $13-$ 19.

[10] M. J. Nicol, H. Miki, S. Zhang, P. Basson Hydrometallurgy 2013, 133, 188196.

[11] G. H. Kelsall, Q. Yin, D. J. Vaughan, K. E. R. England, N.P. Brandon, J. Electroanal. Chem. 1999, 471, 116-125.

[12] L. J. Bryson, F. K. Crundwell, Hydrometallurgy 2014, 143, 42-53.

[13] M. N. Lehmann, M. Stichnoth, D. Walton, S. I. Bailey, J. Electrochem. Soc. 2000, 147, 3263-3271.

[14] C. Mustin, J. Berthelin, P. Marion, P. De Donato, Appl. Environ. Microbiol. 1992, 58, 1175-1182.

[15] V. P. Evangelou, A. K. Seta, A. Holt, Environ. Sci. Technol. 1998, 32, 20842091.

[16] Y. Ma, C. Lin Sci. Rep. 2013, 3, 1979.

[17] S. Bae, D. Kim, W. Lee, App. Catal. B 2013, 134-135, 93-102.

[18] Y. Zhang, K. Zhang, C. Dai, X. Zhou, H. Si, Chem. Eng. J. 2014, 244, 438445.

[19] N. Barhoumi, N. Oturan, H. Olvera-Vargas, E. Brillas, A. Gadri, S. Ammar, M. A. Oturan, Water Res. 2016, 94, 52-61.

[20] F. Demoisson, M. Mullet, B. Humbert, Environ. Sci. Technol. 2005, 39, 8747-8752.

[21] J. B. Hiskey, P. P. Phule, M. D. Pritzker, Metal. Trans. B 1987, 18B, 641647.

[22] A. Ghahremaninezhad, R. Radzinski, T. Gheorghiu, D. G. Dixon, E. Asselin Hydrometallurgy 2015, 155, 95-104.

[23] G. M. Bancroft, G. Jean, Nature 1982, 298, 730-731.

[24] M. M. Hyland, G. M. Bancroft Geochim. Cosmochim. Acta 1989, 53, 367372.

[25] P. Muller, G. Kersten, Miner. Deposita 1994, 29, 404-413.

[26] J. R. Mycroff, G. M. Bancroft, N. S. Mcintyre, J. W. Lorimer, Geochim. Cosmochim. Acta 1995, 59, 3351-3365.

[27] L. M. Maddox, G. M. Bancroft, M. J. Scaini, J. W. Lorimer, Am. Mineral. $1998,83,1240-1245$.

[28] Y. L. Mikhlin, A. S. Romanchenko, Geochim. Cosmochim. Acta 2007, 71, 5985-6001.

[29] T. Groenewald, Hydrometallurgy 1976, 1, 277-290.

[30] C. K. Chen, T. N. Lung, C. C. Wan, Hydrometallurgy 1980, 5, 207-212.

[31] R. Zou, X. Guo, J. Yang, D. Li, F. Peng, L. Zhang, H. Wang, Hao Yu, CrystEngComm 2009, 11, 2797-2803.

[32] I. Turyan, M. Etienne, b, D. Mandler, W. Schuhmann, Electroanalysis 2005, 17, 538-542.

[33] T. Danieli, N. Gaponik, A. Eychmuller, D. Mandler, J. Phys. Chem. C 2008, 112, 8881-8889.

[34] R. G. Fedorov, D. Mandler, J. Phys. Chem. C 2016, 120, 15608-15617.

[35] P. R. Unwin, J. V. Macpherson, R. D. Martin and C. F. McConville, in International Symposium on Localized In Situ Methods for Investigating Electrochemical Interfaces, ed. S. R. Taylor, A. C. Hillier and M. Seo, Honolulu, Hi 1999, 99, 104-121.

[36] O. de Abril, D. Mandler, P. R. Unwin, Electrochem. Solid-State Lett. 2004, 7, C71-C74.

[37] S. Meltzer, D. Mandler J. Electrochem. Soc. 1995, 142, L82-L84.

[38] E. Ammann, D. Mandler, J. Electrochem. Soc. 2001, 148, C533-C539.

[39] E. Malel, D. Mandler, J. Electrochem. Soc. 2008, 155, D459-D467.

[40] M. Sheffer, V. Martina, R. Seeber, D. Mandler, Isr. J. Chem. 2008, 48, 349357.

[41] M. Sheffer, D. Mandler, Electrochim. Acta 2009, 54, 2951-3234.

[42] E. Malel, R. Ludwig, L. Gorton, D. Mandler, Chem. Eur. J. 2010, 16, 1169711706.

[43] T. Danieli, J. Colleran, D. Mandler, Phys. Chem. Chem. Phys. 2011, 13, 20345-20353.

[44] R. G. Fedorov, D. Mandler, Phys. Chem. Chem. Phys. 2013, 15, 2725-2732.

[45] H. Moslemi, P. Shamsi, F. Habashi, Miner. Eng. 2011, 24, 1038-1045.

[46] M. Descostes, P. Vitorge, C. Beaucaire, Geochim. Cosmochim. Acta 2004, 68, 4559-4569.

[47] P. Bonnissel-Gissinger, M. Alnot, J.-J. Ehrhardt, P. Behran, Environ. Sci. Technol. 1998, 32, 2839-2845.

[48] M. Tian, Wendy G. Pell, Brian E. Conway, Corros. Sci. 2008, 50, 26822690.

[49] M. B. Hariri, A. Dolatiz, R. S. Moakhar, J. Electrochem. Soc. 2013, 160, D279-D288.

[50] F. Li, M. Edwards, J. D. Guo, P. R. Unwin, J. Phys. Chem. C 2009, 113, 3553-3565. 
[51] M. E. Hyde, O. V. Klymenko, R. G. Compton, J. Electroanal. Chem. 2002, 534, 13-17.

[52] C. Combellas, F. Kanoufi, D. Mazouzi, J. Phys. Chem. B 2004, 108, 19260 19268.

[53] C. Adam, F. Kanoufi, N. Sojic, M. Etienne, Electrochim. Acta 2015, 179, 45-56.

[54] T. J. Davies, R. G. Compton, J. Electroanal. Chem. 2005, 585, 63-82.

[55] A. Milchev, J. Electroanal. Chem. 1998, 457, 35-46.

[56] H. V. Patten, S. C. S. Lai, J. V. Macpherson, P. R. Unwin, Anal. Chem. 2012, 84, 5427-5432.

[57] B. D. B. Aaronson, C.-H. Chen, H. Li, M. T. M. Koper, S. C. S. Lai, P. R. Unwin, J. Am. Chem. Soc. 2013, 135, 3873-3880.

[58] A. Oleinick, J. Yan, B. Mao, I. Svir, C. Amatore, ChemElectroChem 2016, 3, 487-494.

[59] G. Mettela, G. U. Kulkarni, Nano Res. 2015, 8, 2925-2934.

[60] M. R. Hauwiller, L. B. Frechette, M. R. Jones, J. C. Ondry, G. M. Rotskoff, P. Geissler, A. P. Alivisatos, Nano Lett. 2018, 18, 5731-5737.

[61] C. A. Constantin, P. Chirita, J. Appl. Electrochem. 2013, 43, 659-666.

[62] K. Sasaki, M. Tsunekawa, T. Ohtsuka, H. Konno, Geochim. Cosmochim. Acta 1995, 59, 3155-3158.
[63] C. O. Moses, D. Kirk Nordstrom, J. S. Herman Aaron, L. Mills, Geochim. Cosmochim. Acta 1987, 51, 1561-1571.

[64] V. Brasiliense, J.-M. Noël, K. Wonner, K. Tschulik, C. Combellas, F. Kanoufi, ChemElectroChem 2018, 5, 3036-3043.

[65] Scanning Electrochemical Microscopy, ed. A. J. Bard, M. V. Mirkin, Taylor \& Francis, New York, 2nd edn, 2012

[66] S. Amemiya, A. J. Bard, F.-R. F. Fan, M. V. Mirkin, P. R. Unwin, Annu. Rev. Anal. Chem. 2008, 1, 95-131.

[67] G. Wittstock, M. Burchardt, S. E. Pust, Y. Shen, C. Zhao, Angew. Chem. Int. Ed. 2007, 46, 1584-1617; Angew. Chem. 2007, 119, 1604-1640.

[68] R. Cornut, C. Lefrou, J. Electroanal. Chem. 2007, 608, 59-66.

[69] R. Cornut, C. Lefrou, J. Electroanal. Chem. 2008, 621, 178-184. 